\title{
ERRATUM
}

Andrzej Kaim • Bogdan Jurkovšek •

Tea Kolar-Jurkovšek

\section{New associations of Carnian gastropods from Mežica region in the Karavanke Mountains of Slovenia}

Published online: 4 July 2006

(C) Springer-Verlag 2006

\section{DOI 10.1007/s10347-005-0040-2}

In the line above the DOI and in the copyright line the publishing year was misprinted. It should have read "2006" instead of "2005".

The online version of the original article can be found at http://dx.doi.org/10.1007/s10347-005-0040-2

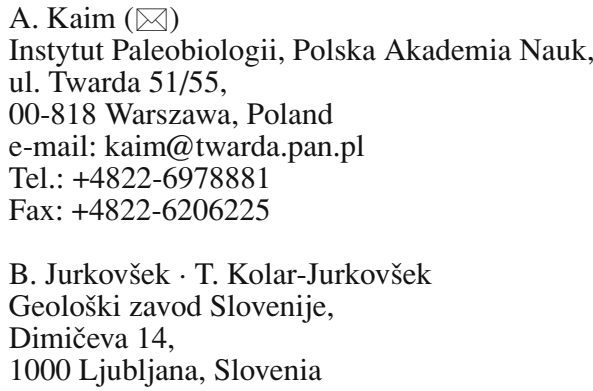

